\title{
EMBALAGENS ALIMENTÍCIAS ACESSÍVEIS: UM LEVANTAMENTO DE SISTEMAS DE INFORMAÇÃO VOLTADOS PARA O DEFICIENTE VISUAL
}

\author{
Marllon de Oliveira Freitas \\ Universidade Federal da Paraíba/CCAE/DDesign \\ marllonsatierf@hotmail.com \\ Angélica de Souza Galdino Acioly \\ Universidade Federal da Paraíba/CCAE/DDesign \\ angelica@ccae.ufpb.br
}

Resumo: De modo geral, a indisponibilidade da informação é um desafio constante para o deficiente visual. Mesmo com o surgimento e propagação da escrita braille são escassos os produtos e serviços criados pensando na comunicação tátil. Apesar da existência significativa de brasileiros com esta deficiência, 18,8\% da população, ou seja, cerca de 34 milhões de brasileiros (IBGE, 2010). Em relação às embalagens de alimentos, a informação sobre o conteúdo embalado é fundamental para o consumidor. São poucas as embalagens que dispõem de informações acessíveis ao deficiente visual (severa ou baixa visão), tornando-o por vezes, dependente de outras pessoas para a realização de uma simples compra. Muitos buscam identificar o alimento pela forma, textura, material da embalagem ou ainda pelo cheiro do produto. Partindo do princípio, que os rótulos das embalagens são o principal meio de comunicação entre o consumidor e o produto, os mesmos deveriam possuir sistemas acessíveis também a este público. Sendo assim, esta pesquisa pretende conhecer quais sistemas tem sido usados em embalagens alimentícias para informar ao deficiente visual sobre o produto embalado. Para tanto, esta pesquisa pode ser caracterizada como um levantamento bibliométrico sobre embalagens e sistemas de informação voltados a atender deficientes visuais, assim como sobre as principais barreiras de acessibilidade encontradas nas embalagens atuais. Para a pesquisa foram levantados artigos científicos de congressos e periódicos, monografias, teses e dissertações, relacionados ao Design de Embalagens e áreas correlatas, publicados entre os anos 2010 e 2016. Até o momento, os resultados prévios da pesquisa mostram que, apesar do número significativo de deficientes visuais, são poucas as categorias de embalagens que adotam o sistema de informação mais usual para este público - rótulos com informação em braile. Seja através da impressão em relevo quando em materiais aplicáveis, ou ainda em rótulos autoadesivos. Sobre as informações apresentadas em braille nas embalagens, Molina (2015) coloca que, as mesmas comumente são referentes apenas ao nome do produto, peso ou quantidade em unidades, e o número do Serviço de Atendimento ao Consumidor (SAC), pois o espaço disponível nem sempre é suficiente para transcrever outras informações em braille. Além dos 
sistemas físicos, foram encontrados sistemas virtuais em Realidade Aumentada, com vistas a auxiliar consumidores que apresentam redução de acuidade visual. Mesmo não sendo aplicados para a cegueira total, tal sistema pode ser analisado para possível uso em baixa visão, com o auxilio também da interface auditiva. Com os resultados desta pesquisa, pretende-se compreender melhor as embalagens $e$ os sistemas desenvolvidos até o momento com foco na informação, a fim de contribuir para o projeto de produtos/sistemas que possibilitem o acesso adequado dos deficientes visuais à esta categoria de produtos. Além deste levantamento, serão realizados na etapa posterior, uma pesquisa para identificar embalagens de alimentos existentes no mercado brasileiro que adotem algum sistema de acessibilidade para este público.

Palavras-chave: Deficiente visual, Embalagens alimentícias, SIstema de informação. 